\title{
Transcription of naked double-stranded RNA molecules in a fraction containing large vesicles plus mitochondria from the basidiomycete Agrocybe aegerita
}

\author{
GÉRARD BARROSO and JACQUES LABARÈRE*
}

Laboratoire de Génétique Moléculaire et d'Amélioration des Champignons Cultivés, Université de Bordeaux II-INRA, CRA de Bordeaux, BP 81, 33883 Villenave d'Ornon Cedex, France

(Received 10 June 1992; revised 4 September 1992; accepted 23 September 1992)

\begin{abstract}
Actinomycin D-resistant RNA synthesis was detected in the cellular (VM) fraction which contains large vesicles plus mitochondria from Agrocybe aegerita. It involved the RNAase-resistant complex of naked (unencapsidated) double-stranded RNAs (dsRNAs). The RNA polymerase assay showed $\left[\alpha-{ }^{32}\right.$ P]UTP incorporation in dsRNAs of a size corresponding to the previously described naked M-dsRNAs and in single-stranded RNAs of related size, which are assumed to act as intermediaries in the replicative cycle of the dsRNA molecules. Moreover, the incorporation of ribonucleotides into large mitochondrial dsDNA fragments was detected in the dsRNA-containing strain. This result favours a mitochondrial location for the naked dsRNAs and their associated polymerizing enzyme(s). No replication of the encapsidated large L-dsRNA viral genome was detected in the VM fraction, supporting the hypothesis that the two types of dsRNAs observed in this $A$. aegerita strain are independent entities.
\end{abstract}

\section{Introduction}

In lower eukaryotes, such as fungi or protozoa, most of the viruses store their genetic information in doublestranded RNA (dsRNA) molecules, whose transcription and replication are DNA-independent. These dsRNA segments are generally encapsidated in isometric virus particles (for reviews, see Buck, 1986 and Patterson, 1990). However, besides these typical viral genomes, naked (unencapsidated) dsRNAs have been described which are located in membranous structures (vesicles or mitochondria) of parasitic or saprophytic fungi (Rogers et al., 1987; Barroso \& Labarère, 1990).

The best studied of the naked dsRNAs are those associated with hypovirulence of the chestnut blight fungus Cryphonectria (Endothia) parasitica (Anagnostakis, 1982). By sequencing the largest (12712 bp) dsRNA (LdsRNA) present in a hypovirulent strain of this parasitic fungus, Shapira et al. (1991 a) have shown that, although dsRNAs are not packaged within particles and do not exhibit an extracellular phase, their organization and expression strategies are closely related to viral genetic information. In this context, they propose the introduction of hypovirulence-associated virus (HAV) as a

\footnotetext{
*Author for correspondence. Tel. 568431 69; fax 56843274.
}

descriptive term for these dsRNAs. Moreover, they demonstrate that the smaller dsRNA molecules (from 10 to $0.6 \mathrm{kbp}$ ) of the hypovirulent strains are the result of the generation and maintenance of internally deleted forms of the L-dsRNA (Shapira et al., 1991b).

In another pathogenic fungus, Ophiostoma ulmi, Rogers et al. (1987) established that the dsRNA segments of the fungal diseased isolates copurified with mitochondria and were associated with a cytochrome $\mathrm{aa}_{3}$ deficiency.

In the saprophytic edible basidiomycete Agrocybe aegerita, two types of RNAase-resistant complexes have been found. The first complex was the encapsidated genome (L-dsRNA of $6200 \mathrm{bp}$ ) of an isometric mycovirus; the second one comprised naked M-dsRNAs (three molecules of closely related size from 1900 to $1700 \mathrm{bp}$ ) associated with the large vesicles and mitochondria (VM) cellular fraction (Barroso \& Labarère, 1990). In contrast to the discrete viral L-dsRNA molecule, M-dsRNAs were recovered in large quantities from the infected strain $(10 \mu \mathrm{g}$ M-dsRNAs from $20 \mathrm{~g}$ dried vegetative mycelium). However, the two types of molecules were, at that time, cryptic, i.e. their presence was not related to a phenotype or a modification of the hyphal growth or physiology (Barroso \& Labarère, 1990).

To study the replication and the relationship between 
the dsRNAs of the two RNAase-resistant complexes of the $A$. aegerita strain, we have investigated the location and characterization of the dsRNA synthesizing enzyme of each complex.

\section{Methods}

Strains and cultures. The tetrapolar basidiomycete Agrocybe aegerita belongs to the class Agaricales. The wild dikaryotic strains used, SM47 (mating-type alleles: $A 7 A 8$ B4B7) and SM51 (A3A4 B3B4), were derived from in vitro cultures of fragments of fruiting bodies collected from nature. The dikaryotic strain SM47 was cultivated in vitro to obtain basidiocarps from which homokaryotic progeny Al was obtained (Noël et al., 1991). The two strains SM51 and Al were shown to lack dsRNA molecules and, accordingly, were used as controls in the RNA polymerase assays. Both homokaryotic and dikaryotic vegetative mycelia were cultivated on solid or liquid complete CYM medium (Raper et al., 1972). Growth of the vegetative mycelium was obtained in Roux culture flasks, at $28^{\circ} \mathrm{C}$ in the dark. After incubation, mycelium was harvested by filtration on sterilized gauze, washed with distilled water, squeezed within the gauze to remove excess water and weighed.

Cellular fractionation. Twenty grams of dried vegetative mycelium was disrupted in $30 \mathrm{ml}$ cold $15 \%$ sucrose suspension buffer (SSB: sucrose $15 \%$, w/v, $10 \mathrm{~mm}$-Tris $/ \mathrm{HCl} \mathrm{pH} 6 \cdot 8$, BSA $0 \cdot 1 \%$, w/v, $5 \mathrm{~mm}-\beta$ mercaptoethanol) using a homogenizer (model $\mathrm{HO}_{4}$ from Edmund Bühler: $30 \mathrm{~s}$ at 20000 r.p.m., $5 \mathrm{~s}$ at 30000 r.p.m. and $5 \mathrm{~s}$ off, twice), then filtered through four layers of sterile gauze without squeezing the hyphae, to eliminate remaining large hyphal fragments. The filtrate was centrifuged once at low speed $\left(2500 \mathrm{~g}, 10 \mathrm{~min}, 4^{\circ} \mathrm{C}\right)$ to remove nuclei and large membrane and cell wall fragments. DNAase $\mathrm{I}\left(100 \mu \mathrm{g} \mathrm{ml}^{-1}\right)$, $\mathrm{MgCl}_{2}(10 \mathrm{mM})$ and RNAase A $\left(100 \mu \mathrm{g} \mathrm{m}^{-1}\right)$ were added to the supernatant and incubated for $30 \mathrm{~min}$ at $37^{\circ} \mathrm{C}$. Then, a second low speed centrifugation was carried out. One volume of $15 \%$ sucrose containing $100 \mathrm{mM}$-EDTA was added to the supernatant and the whole was subjected to ultracentrifugation $\left(85000 \mathrm{~g}, 150 \mathrm{~min}, 4^{\circ} \mathrm{C}\right.$; Kontron T-2070 centrifuge with a TFT 70-38 rotor).

For sucrose gradient fractionation, the $\mathrm{C}_{85000}$ pellet was resuspended in $1 \mathrm{ml} \mathrm{SSB}$, then layered on the top of a discontinuous gradient $\left(200000 \mathrm{~g}, 150 \mathrm{~min}, 4^{\circ} \mathrm{C}\right.$; TST $55-5$ rotor). The discontinuous sucrose gradient was preformed by adding successive $1 \mathrm{ml}$ layers of $60,45,30$ and $20 \%$ sucrose. After centrifugation, the gradient was fractionated using the Helirac 2212 (LKB). The mitochondria were obtained as a broad band in the $45 \%$ sucrose layer and shown by electron microscopy to be contaminated by large vesicles of related size (Barroso \& Labarère, 1990). This large vesicles plus mitochondria sub-cellular fraction was called VM fraction.

Purification of virus particles. Viral nucleocapsids were recovered from the $\mathrm{C}_{85000}$ pellet by a $5 \mathrm{ml}$ discontinuous sucrose gradient centrifugation $\left(60-45-30-20-15 \%\right.$ sucrose; $250000 \mathrm{~g}, 150 \mathrm{~min}, 4^{\circ} \mathrm{C}$; TST 55-5 rotor) and further purified by an isopycnic centrifugation $\left(250000 \mathrm{~g}, 150 \mathrm{mins}, 4^{\circ} \mathrm{C}\right.$; TST $55-5$ rotor) through a preformed $\mathrm{CsSO}_{4}(15-20-30-45-60 \%$, w/v) density gradient. The nucleocapsid band was recovered, diluted in $5 \mathrm{ml}$ sterile distilled water, pelleted by centrifugation $\left(250000 \mathrm{~g}, 150 \mathrm{~min}, 4^{\circ} \mathrm{C}\right.$; TST $55-5$ rotor $)$ and resuspended in $100 \mu \mathrm{l}$ sterile distilled water.

RNA polymerase assay. The standard reaction mixture contained, in a final volume of $200 \mu \mathrm{l}: 100 \mathrm{mM}$-Tris $/ \mathrm{HCl} \mathrm{pH} \mathrm{7.5,10} \mathrm{mM-magnesium}$ acetate, $1 \mathrm{mM}$ each of ATP, CTP, GTP and UTP, $10 \mu \mathrm{Ci}$ of $\left[\alpha_{-}^{32} \mathrm{P}\right] \mathrm{UTP}$ (Amersham; $3000 \mathrm{Ci} \mathrm{mmol}^{-1} ; 1 \mathrm{Ci}=37 \mathrm{GBq}$ ) and $100 \mu$ lof the VM fraction or viral nucleocapsids. $\mathrm{pH} 7.5$ was previously established as the optimum $\mathrm{pH}$ for the RNA-dependent RNA polymerase activity associated with the Saccharomyces cerevisiae killer dsRNA virion (Welsh et al., 1980) or with a virus-enriched fraction of the basidiomycete Agaricus bisporus (Sriskantha et al., 1986). In the same way, the magnesium acetate concentration was equal to $10 \mathrm{~mm}$, an intermediate concentration between the optimal concentrations of 5 and $15 \mathrm{~mm}$ for the RNA replicase activity of the $S$. cerevisiae and Ustilago maydis dsRNA virus (Welsh et al., 1980; Ben-Tzvi et al., 1984), and of the 'La France' disease virus partially purified from A. bisporus basidiocarps (Sriskantha et al., 1986), respectively. Forty units of human placenta ribonuclease inhibitor and actinomycin D $\left(100 \mu \mathrm{g} \mathrm{ml}^{-1}\right)$ were added. The RNA polymerase reaction was allowed to proceed at $28^{\circ} \mathrm{C}$, for $16 \mathrm{~h}$. The reaction was stopped by lysing the cellular or viral fraction by addition of SDS to a final concentration of $2 \%(\mathrm{w} / \mathrm{v})$. Each RNA polymerase assay reported in the text was performed at least in triplicate with, in each case, a cellular or viral fraction arising from independent mycelium cultures.

In some experiments, the RNA polymerase assay was carried out in the presence of DNAase I (Sigma) or RNAase A at a final concentration of $25 \mu \mathrm{g} \mathrm{m}^{-1}$, at low (standard conditions) or high $(2 \times \mathrm{SSC}: 0.3 \mathrm{M}-$ $\mathrm{NaCl}, 0.03 \mathrm{M}$-sodium citrate) salt concentration. In these cases, the human placenta ribonuclease inhibitor (HPRI; Appligene) was omitted. The nucleic acid hydrolases were eliminated by $30 \mathrm{~min}$ incubation at $37^{\circ} \mathrm{C}$ with $50 \mu \mathrm{g}$ proteinase $\mathrm{K} \mathrm{ml} \mathrm{m}^{-1}$, then $15 \mathrm{~min}$ at $56^{\circ} \mathrm{C}$ in the presence of $2 \% \mathrm{SDS}$, followed by a phenol treatment for $15 \mathrm{~min}$ at $56^{\circ} \mathrm{C}$.

Extraction and analysis of nucleic acids. Nucleic acids were extracted from $\mathrm{C}_{85000}$, from $\mathrm{VM}$ fraction or from purified nucleocapsids, after lysis in SDS at a final concentration of $2 \%$ for $120 \mathrm{~min}$ at $56^{\circ} \mathrm{C}$. Then, a volume of phenol (saturated with TE buffer) was added. The resulting emulsion was centrifuged $\left(8000 \mathrm{~g}, 10 \mathrm{~min}, 4^{\circ} \mathrm{C}\right)$. The aqueous phase was taken and added to an equal volume of chloroform/isoamyl alcohol $(24: 1, \mathrm{v} / \mathrm{v})$. The emulsion was treated as described above for the phenol emulsion. The nucleic acids were precipitated with 2 vols $95 \%(\mathrm{w} / \mathrm{v})$ ethanol in the presence of $0.3 \mathrm{M}$-sodium acetate for $120 \mathrm{~min}$ at $-20^{\circ} \mathrm{C}$, then pelleted by centrifugation and resuspended in sterile distilled water. The radioactivity of the pellet was determined using a liquid scintillation counter (Kontron).

Agarose gel electrophoresis and autoradiography. The nucleic acids were analysed in a horizontal $0.8 \%(\mathrm{w} / \mathrm{v})$ agarose gel buffered in TBE (0.09 $\mathrm{M}$-Tris/HCl, 0.09 м-boric acid, 0.002 M-EDTA). Nucleic acids were visualized by ethidium bromide staining (Maniatis et al., 1982). For autoradiography, the gel was incubated twice for $15 \mathrm{~min}$ in $10 \%$ $(\mathrm{w} / \mathrm{v})$ acetic acid then dried between sheets of Whatman 3MM chromatography paper. The dried gel was placed in a plastic bag and exposed to Kodak XAR-5 film at $-80^{\circ} \mathrm{C}$ with an intensifying screen (Cronex).

In vitro manipulations of nucleic acids. DNAase I (Sigma) digestions were carried out in the presence of $10 \mathrm{mM}-\mathrm{MgCl}_{2}$. RNAase A (Sigma) digestion tests were performed in sterile distilled water or in $2 \times \mathrm{SSC}$ for $30 \mathrm{~min}$ at $37^{\circ} \mathrm{C}$. Then, to eliminate the enzyme, proteinase $\mathrm{K}$ was added in $2 \times \mathrm{SSC}$ at a final concentration of $50 \mu \mathrm{g} \mathrm{ml}^{-1}$, incubated at $37^{\circ} \mathrm{C}$ for another $30 \mathrm{~min}$ and a volume of phenol was added. The resulting emulsion was centrifuged. Nucleic acids of the aqueous phase were precipitated by 2 vols $95 \%$ ethanol, pelleted by centrifugation, resuspended in sterile distilled water and analysed by agarose gel electrophoresis.

Estimation of the size of the nucleic acids. The nucleic acid fragment sizes were estimated from the relative rate of migration in $0.8 \%$ agarose gel electrophoresis in TBE buffer by comparison with HindIII-cleaved $\lambda$ DNA for DNA fragments, dsRNA segments of the maize rough dwarf fijivirus, as described previously, for dsRNAs (Barroso \& 
Labarère, 1990), and the 0.24-9.5 kb RNA ladder from Gibco-BRL for ssRNAs.

\section{Results}

The vegetative mycelia of the dikaryotic $A$. aegerita SM47, SM51 wild-type strains and of the homokaryotic progeny A1 were disrupted in $15 \%$ SSB to avoid osmotic lysis of the cellular organelles. These subcellular organelles were then separated by differential centrifugation $(2500 \mathrm{~g}$ twice followed by ultracentrifugation at $85000 \mathrm{~g}$ ) in the presence of DNAase I and RNAase A, as described in Methods. As reported previously (Barroso \& Labarère, 1990), an electrophoretic analysis of nucleic acids from the $\mathrm{C}_{85000}$ pellet of SM47 revealed three types of molecules (Fig. 1, lane B): (i) the high $M_{\mathrm{r}}$ dsDNA fragments resulting from mechanical breakage of the mitochondrial genome during nucleic acid extraction (Moulinier et al., 1992), (ii) the quantitatively minor encapsidated L-dsRNA (6200 bp) and (iii) the major naked M-dsRNA molecules resolved into two bands $\left(\mathbf{M}_{1}\right.$ and $\mathrm{M}_{2}$ ) of related size $(1900-1700 \mathrm{bp}$ ) by agarose gel electrophoresis.

Only the mtDNA fragments were seen in the $\mathrm{C}_{85000}$ pellets of the SM47 homokaryotic progeny A1 (Fig. 1, lane A), or from the dikaryotic strain SM51 (Barroso \& Labarère, 1990). No dsRNA molecule was evident in these two strains. The same negative result was obtained with both these strains using the 'miniprep' dsRNAs extraction procedure of Seroussi et al. (1989).

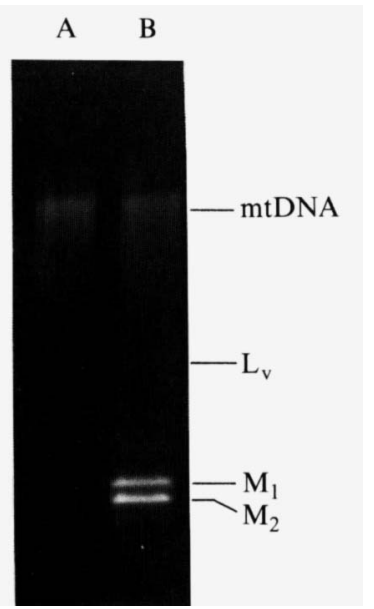

Fig. 1. Agarose (0.8\%) gel electrophoresis patterns of the nucleic acids from the $\mathrm{C}_{85000}$ pellet from the dikaryotic strain SM47 (lane B) and its homokaryotic progeny A1 (lane A). Nucleic acids were visualized by ethidium bromide staining. mtDNA indicates the high $M_{\mathrm{r}}$ fragments resulting from mechanical breakage of the mitochondrial genome during nucleic acid extraction. $L_{v}, M_{1}$ and $M_{2}$ represent the large $(6200 \mathrm{bp})$ encapsidated viral genome and the naked dsRNAs (1900-1700 bp) previously described in the SM47 strain (Barroso \& Labarère, 1990), respectively. For experimental details, see Methods.
The $\mathrm{C}_{85000}$ pellets from the three strains were resuspended in SSB and fractionated on a discontinuous sucrose gradient. Each of the three pellets was resolved as a broad band in the $45 \%$ sucrose layer which did not enter the $60 \%$ sucrose cushion. This band (VM fraction) was shown, by electron microscopy, to consist of large vesicles and mitochondria (Barroso \& Labarère, 1990). mtDNA fragments and the naked M-dsRNAs from SM47 were recovered mainly in this VM fraction. Indeed, this fraction was demonstrated previously to package naked dsRNAs in a RNAase-resistant membranous complex. In the corresponding fraction purified from the homokaryotic progeny A1, as well as from SM51, only mtDNA fragments were seen.

In addition, from extracts of SM47, the sucrose gradient fractionation allowed recovery of a second thin light-scattering band at the $20-30 \%$ sucrose interface. This band was previously shown to consist of nucleocapsids including a $6200 \mathrm{bp}$ L-dsRNA genome in a RNAase-resistant complex (Barroso \& Labarère, 1990). This band was not seen in the extracts of the other two strains.

The presence of a RNA polymerizing system was investigated in the two types of RNAase-resistant complexes from the SM47 strain: the L-dsRNA including nucleocapsid and the M-dsRNAs including VM fraction. This subcellular fraction was compared with the corresponding ones, purified from the dsRNA-free SM51 and $\mathrm{A} 1$ strains, used in control experiments.

\section{$R N A$ synthesis by the $M$-dsRNA-packaging $V M$ fraction}

RNA synthesis activity of the $A$. aegerita SM47 VM fraction was investigated by electrophoretic analysis of the products incorporating $\left[\alpha-{ }^{32} P\right] U T P$. For this, the fraction was incubated in the presence of the four nucleoside triphosphates (ATP, CTP, UTP and GTP;

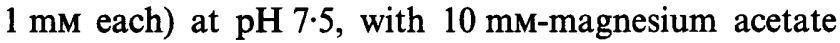
and $10 \mu \mathrm{Ci}\left[\alpha-{ }^{32} \mathrm{P}\right] \mathrm{UTP}$. Forty units of human placenta ribonuclease inhibitor and actinomycin $\mathrm{D}$ at a final concentration of $100 \mu \mathrm{g} \mathrm{ml}^{-1}$ were added to inhibit cellular RNAase and transcriptional activity, respectively.

The membranes of the VM fraction were submitted to SDS (2\%) treatment before and after 1, 2, 4 and $16 \mathrm{~h}$ incubation at $28{ }^{\circ} \mathrm{C}$ (i.e. the optimal mycelial growth temperature) under the conditions of the RNA synthesis assay. The nucleic acids were extracted and ethanolprecipitated. After $16 \mathrm{~h}$ incubation, the nucleic acid pellet had a specific radioactivity higher than $10^{7}$ c.p.m. The nucleic acids were separated by agarose gel electrophoresis and revealed by ethidium bromide staining as well as by autoradiography of the fixed and dried 


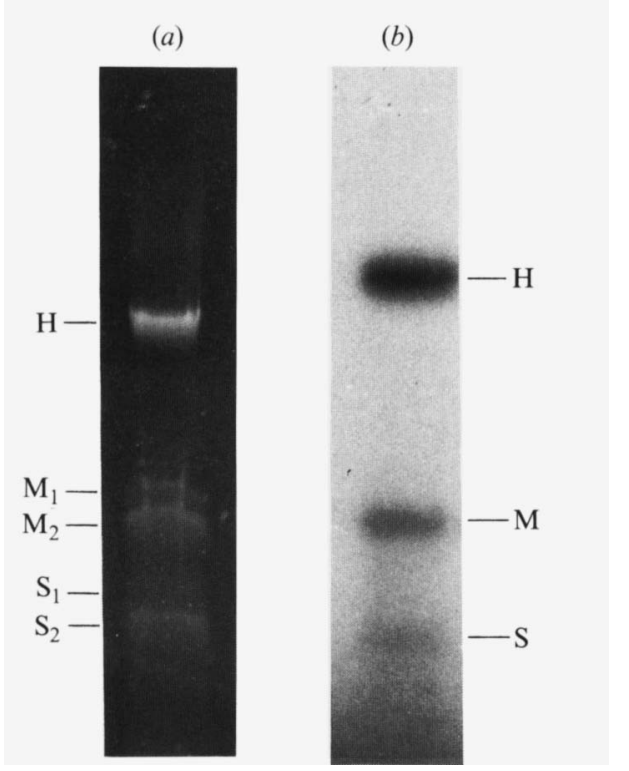

Fig. 2. Agarose $(0.8 \%)$ gel electrophoresis pattern (a) and autoradiogram $(b)$ of the nucleic acids extracted from the SM47 VM fraction after $16 \mathrm{~h}$ incubation under RNA polymerase assay conditions. The symbols $\mathrm{H}, \mathbf{M}_{1}, \mathbf{M}_{2}, \mathbf{M}, \mathrm{S}_{1}, \mathrm{~S}_{2}$ and $\mathrm{S}$ are defined in Results. For experimental details, see Methods.

agarose gel (Fig. $2 a$ and $b$ ). As shown in the autoradiograms, after $16 \mathrm{~h}$ incubation under the conditions of the RNA synthesis assay, all the nucleic acids of the fraction which were visible by ethidium bromide staining had incorporated $\left[\alpha-{ }^{32} \mathrm{P}\right]$ UTP. More precisely, three types of nucleic acid molecules were detected on the gels and autoradiograms: (i) a high $M_{\mathrm{r}}$ band $(\mathrm{H})$, with an apparent size $>20 \mathrm{kbp}$, (ii) two bands, $\mathbf{M}_{1}$ and $\mathbf{M}_{2}$, with the same electrophoretic mobility as the naked M-dsRNAs molecules, and (iii) two additional bands, $S_{1}$ and $S_{2}$, of smaller size.

The kinetics of labelling of the three types of molecules differed : a slight incorporation of $\left[\alpha{ }^{32} P\right] U T P$ was evident in the $\mathrm{M}$ and $\mathrm{S}$ bands after $1 \mathrm{~h}$ of the RNA polymerase assay. In contrast, the $\mathrm{H}$ band was detected on the autoradiograms only after a longer time, i.e. between 4 and $16 \mathrm{~h}$ incubation.

It should be noted that, during gel fixing and drying, the faint nucleic acid bands tended to spread out and, accordingly, the similarly sized $\mathrm{M}_{1}$ and $\mathrm{M}_{2}$ and $\mathrm{S}_{1}$ and $\mathrm{S}_{2}$ bands were resolved in two unique broader bands on the autoradiograms.

Identical electrophoretic patterns and autoradiograms were obtained when, not only the cellular fractionation leading to the VM fraction, but also the replicative assay was carried out in the presence of $25 \mu \mathrm{g}$ DNAase I ml $\mathrm{I}^{-1}$ and $25 \mu \mathrm{g}$ RNAase $\mathrm{A} \mathrm{m}^{-1}$ (Fig. 3, lane $\mathrm{T}^{\prime}$ ). This result confirms the location of the templates and enzymes

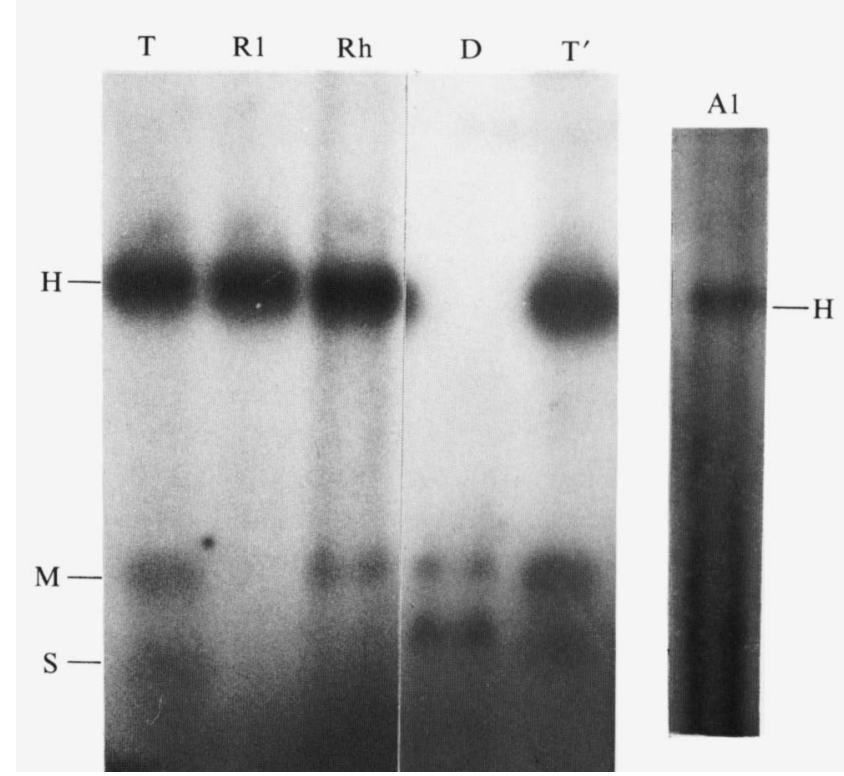

Fig. 3. Autoradiograms of the nucleic acids extracted from the SM47 VM fraction after $16 \mathrm{~h}$ incubation under RNA polymerase assay conditions $(T)$, then submitted to various hydrolytic treatments: digestion by RNAase A $\left(5 \mu \mathrm{g} \mathrm{m}^{-1}\right)$ in sterile distilled water (Rl) or $2 \times \operatorname{SSC}(\mathrm{Rh})$, or digestion by DNAase $\mathrm{I}\left(5 \mu \mathrm{g} \mathrm{m}^{-1}\right)$ in the presence of $10 \mathrm{mM}^{-\mathrm{MgCl}_{2}}$ (D). Nucleic acids were separated by agarose $(0.8 \%)$ gel electrophoresis before autoradiography. $T^{\prime}$ represents the autoradiogram of the nucleic acids from the SM47 VM fraction, after a $16 \mathrm{~h}$ RNA polymerase assay carried out in the presence of $25 \mu \mathrm{g}$ DNAase I and RNAase $\mathrm{A} \mathrm{ml}^{-1}$. Al represents the autoradiogram of the nucleic acids extracted from the VM fraction purified from the control (dsRNA-free) strain Al, and subjected to a $16 \mathrm{~h}$ RNA polymerase assay in the absence of actinomycin D. For experimental details, see Methods.

within an RNAase-impermeable compartment, i.e. within structurally intact cellular organelles.

The ${ }^{32} \mathrm{P}$-labelled nucleic acids extracted from the cellular fraction, after a $16 \mathrm{~h}$ RNA synthesis assay, were submitted to various enzymic treatments, then analysed by agarose gel electrophoresis and autoradiography (Fig. 3).

The $\mathbf{M}_{1}$ and $\mathbf{M}_{2}$ bands were degraded by RNAase $A$ $\left(5 \mu \mathrm{g} \mathrm{ml}^{-1}\right)$ in sterile distilled water, i.e. in low salt concentration (Fig. 3, lane Rl), but were unaffected by the same concentration of RNAase $A$ in the high salt concentration buffer $(2 \times \mathrm{SSC}$; Fig. 3, lane Rh). Hence, the $M_{1}$ and $M_{2}$ bands corresponded to the previously described naked M-dsRNAs, of size 1900-1700 bp.

The small bands $S_{1}$ and $S_{2}$ were degraded by RNAase $A$ in low and high salt concentrations, suggesting that they corresponded to single-stranded RNA (ssRNA) molecules (Fig. 3, lanes Rl and Rh). Accordingly, their sizes were established equal to $1900-1700 \mathrm{pb}$.

As shown in Fig. 3, the high $M_{\mathrm{r}}$ band had the following characteristics: (i) it incorporates $\left[\alpha-{ }^{32} \mathrm{P}\right] \mathrm{UTP}$, (ii) it had the same electrophoretic mobility as the large 
DNA fragments previously assessed as the fragments generated by mechanical breakage of the mtDNA molecule (Barroso \& Labarère, 1990; Moulinier et al., 1992), and (iii) it was degraded by a DNAase I $\left(5 \mu \mathrm{g} \mathrm{ml}^{-1}\right)$ treatment and not by RNAase A or RNAase $\mathrm{H}$ treatment (Fig. 3, lanes D and Rl).

Despite the high sensitivity of detection of the ${ }^{32} \mathrm{P}$ labelled nucleic acids, no incorporation of $\left[\alpha{ }^{32} \mathrm{P}\right] \mathrm{UTP}$ could be detected in a dsRNA molecule of a size corresponding to the viral genome $\mathrm{H} 1(6200 \mathrm{bp})$ in the VM fraction of the SM47 strain.

The RNA polymerase assay was performed also over $16 \mathrm{~h}$, on the dsRNA-free VM fraction from the homokaryotic strain A1 or from the dikaryotic strain SM51, used as control strains. No incorporation of $\left[\alpha-{ }^{32} P\right] U T P$ in nucleic acids was seen in the presence of $100 \mu \mathrm{g}$ actinomycin $\mathrm{D} \mathrm{ml}^{-1}$. In contrast, when actinomycin D was omitted $\left[\alpha{ }^{32} \mathrm{P}\right] \mathrm{UTP}$ was incorporated in the high $M_{\mathrm{r}}$ band corresponding to the mtDNA fragments and mainly in ssRNA molecules leading to a smeary signal from 5000 bp to the bottom of the gel (Fig. 3, lane A1). These results confirm the transcriptional inactivation of the cellular, more precisely mitochondrial, DNA-dependent RNA polymerase by a concentration of actinomycin $\mathrm{D}$ equal to $100 \mu \mathrm{g} \mathrm{ml}^{-1}$. Consequently, all the ${ }^{32}$ P-labelled nucleic acids seen in the VM fraction of the SM47 strain in presence of actinomycin D, seem to be imputed to naked M-dsRNA-associated RNA polymerase activity.

\section{Search for a replicative activity associated with the isometric nucleocapsid}

The isometric nucleocapsids of the virus present in A. aegerita SM47 were purified by fractionation in a discontinuous sucrose gradient in which they were resolved as a faint light-scattering band at the interface of the $20-30 \%$ sucrose layers. The band was recovered and subjected to a centrifugation in a preformed $20-60 \%$ $\mathrm{CsSO}_{4}$ density gradient. A faint light-scattering band of nucleocapsids was obtained at the $20-30 \% \quad \mathrm{CsSO}_{4}$ interface.

The nucleocapsids were used in a RNA synthesis assay carried out under the conditions used for the VM fraction: i.e. in the presence of the four nucleoside triphosphates, at $\mathrm{pH} 7 \cdot 5$, with $10 \mu \mathrm{Ci}\left[\alpha{ }^{32} \mathrm{P}\right] \mathrm{UTP}$, for 1 , 2,4 or $16 \mathrm{~h}$. No incorporation of $\left[\alpha{ }^{32} \mathrm{P}\right] \mathrm{UTP}$ in nucleic acids could be detected on the autoradiograms. The same negative result was obtained when RNA synthesis activity was tested at $5,10,15$ or $20 \mathrm{~mm}$ magnesium acetate. No incorporation of $\left[\alpha{ }^{32} P\right] U T P$ was found when the entire polymerase assay mixture was spotted on a $1 \mathrm{~cm}^{2}$ Whatman $3 \mathrm{MM}$ filter paper and the radioactivity of the trichloroacetic acid precipitate determined, even when nucleocapsids were disrupted by sonication ( $5 \mathrm{~min}$, $50 \mathrm{~W}$; Vibra-cell, Sonics Materials) before the replicase assay.

\section{Discussion}

Our results have demonstrated that $A$. aegerita contains a fraction in which ribonucleotides are incorporated in dsRNA molecules, in a DNA-independent manner, i.e. in an actinomycin D-resistant mode of synthesis, at the vesicular or mitochondrial level. As full-length ssRNAs were produced, this is the first report of the presence of an effective dsRNA transcriptional system in fungal vesicles or mitochondria, although a polymerase activity was detected by $\left[\alpha-{ }^{32}\right.$ P]UTP incorporation in the vesicular RNAase-resistant complex of dsRNAs from the hypovirulent strains of the chestnut blight fungus Cryphonectria parasitica (Hansen et al., 1985). In the same way, naked dsRNA 'plasmids' were shown to replicate in the presence of actinomycin D in mitochondria of maize plants with S-type cytoplasm (Finnegan \& Brown, 1986).

In the $A$. aegerita RNAase-resistant complex packaging the naked dsRNAs, analysis of the [32P]UTP incorporation products revealed three types of molecules in the VM fraction: (i) the previously described naked dsRNA molecules, resolved in two bands $\left(M_{1}\right.$ and $\left.M_{2}\right)$ of related size (around $2000 \mathrm{bp}$ ), (ii) two bands of ssRNAs $\left(S_{1}\right.$ and $\left.S_{2}\right)$ of about 2000 bases, and (iii) ${ }^{32} \mathrm{P}$-labelled high $M_{\mathrm{r}}$ molecules.

Accordingly, our data are consistent with the presence in the membranous complex of a RNA-dependent RNA polymerase able to catalyse the transcription of the $M_{1}$ and $M_{2}$ dsRNA molecules and leading to ribonucleotide incorporation in dsRNA molecules, as described previously for the virion-associated replicase of the Penicillium stoloniferum virus S (Buck, 1975) or of the virus partially purified from 'La France' disease-affected $A$. bisporus basidiocarps (Sriskantha et al., 1986). The presence of this enzyme in the VM fraction strengthens the idea that these naked dsRNAs represent the segmented genome of a mycovirus which has co-evolved with its fungal host (Barroso \& Labarère, 1990). This evolution would have maintained the replicative function in the packaging compartment of the fungal hyphae and allowed a concomitant loss of the capsid and of the viral extracellular phase.

The $S_{1}$ and $S_{2}$ ssRNAs appear as full-length transcripts of the dsRNA molecules or might be considered as replicative intermediates, i.e. they would reflect one part of the replication cycle, as described in the case of the polymerase enzymes associated with $U$. maydis (BenTzvi et al., 1984) or S. cerevisiae virus (Welsh et al., 1980). 
The incorporation of $\left[{ }^{32} \mathrm{P}\right] \mathrm{UTP}$ into the third type of molecules, those with high $M_{\mathrm{r}}$ ones, is more difficult to explain, especially in the light of the fact that a DNAase I treatment is necessary to obtain degradation of the radioactively labelled product. In other basidiomycetes like Coprinus cinereus or A. bisporus, a unique DNA polymerase $\mathrm{b}$ has been detected which is able to polymerase dNTP on activated DNA templates or ss -rRNA templates in the presence of an oligo(dG) $)_{12-18}$ primer, or on dsRNAs without primer (Lu \& Sakaguchi, 1984). By analogy, the [ $\alpha{ }_{-}^{32}$ P]UTP-labelled high $M_{\mathrm{r}}$ molecules might be the result of polymerization of NTP on the mitochondrial dsDNA templates by the dsRNAassociated transcriptional complex. This idea is strengthened by the absence of radioactive labelling of the mtDNA fragments from the dsRNA-free strains SM51 and the homokaryotic progeny Al. In our conditions, i.e. a long time course $(16 \mathrm{~h})$ in presence of actinomycin D, the M-dsRNAs associated RNA polymerase would be able to use mtDNA as template and the newly synthesized ssRNAs would be used as primers for the mtDNA replication system. It is noticeable that this mtDNA replication occurred in organello, when the RNA polymerase activity (DNA dependent) of the VM fraction from the dsRNA-free strains SM51 or A1 was tested in the absence of actinomycin D. However, further work is needed to demonstrate that the incorporation of ribonucleotides in dsRNAs and dsDNAs is catalysed by the same enzyme. If this was the case, the actinomycin D-resistant $\left[{ }^{32}\right.$ P]UTP labelling of the dsRNAs and dsDNAs in presence of DNAase and RNAase, would suggest that all the templates (M-dsRNAs and large dsDNA fragments) are present with RNA polymerizing enzyme in the same intact cellular compartment. Accordingly, data would be in favour of a mitochondrial location of the M-dsRNAs molecules and of the dsRNAs-associated transcriptional complex, as described previously for dsRNA molecules of male-sterile maize (Finnegan \& Brown, 1986) or of the fungus Ophiostoma (Ceratocyctis) ulmi (Rogers et al., 1987). It is of interest that the major mitochondrial naked dsRNAs found in maize cells or in the two fungi $O$. ulmi and $A$. aegerita show a narrow size range (between 1700 and $2900 \mathrm{pb}$ ).

In contrast to the results obtained with the VM fraction, no $\left[\alpha{ }^{32} \mathrm{P}\right] \mathrm{UTP}$ incorporation was detected with partially or extensively $\left(\mathrm{CsSO}_{4}\right.$ gradient- $)$ purified nucleocapsids from the SM47 strain. The absence of replicative or even transcriptional activity associated with the nucleocapsids, can be explained by two hypotheses. First, the two types of dsRNAs molecules (naked and encapsidated) are independent entities replicated by different enzymic systems and our polymerase assay, which allows the labelling of naked
dsRNA molecules by the enzyme located in VM fraction, does not allow the activity of the nucleocapsid-associated replicase. Second, the naked and encapsidated dsRNAs are replicated by the same polymerase enzyme but, contrary to the results obtained with various dsRNA virions, the replicase activity requires a cellular environment or factor, available in the VM fraction but absent from the purified nucleocapsid.

The absence of a ${ }^{32} \mathrm{P}$-labelled dsRNA molecule of a size corresponding to the encapsidated viral genome $(6200 \mathrm{bp})$ in the VM fraction, favours the first hypothesis.

Finally, the results confirm that, although the two types of RNAase-resistant complex seem to have a viral origin, the large (6200 bp) encapsidated dsRNA (possible totivirus; Francki et al., 1991) and the naked MdsRNAs fragments constitute different viral entities which have been maintained in two different forms in the hyphae. In accordance, the nature of the different $A$. aegerita dsRNAs molecules varies greatly from that of the hypovirulent strains of the chestnut blight fungus, C. parasitica, where the complexity of the dsRNA population was shown to be due to defective dsRNAs from the L (12700 bp) HAV dsRNA genome (Shapira $e t$ $a l ., 1991 b$ ). In $A$. aegerita, a primary infection would have led to the appearance and maintenance of the naked M-dsRNAs and of an associated RNA polymerase activity, in a RNAase-protecting fungal compartment (mitochondria or vesicles). However, the role of these naked M-dsRNAs is still unknown. Additionally, the presence in the strain of the isometric cryptic particle would be the result of an independent additional infection by a second mycovirus.

This work was supported by grants from the Conseil Scientifique de l'Université de Bordeaux II and the Institut National de la Recherche Agronomique.

\section{References}

ANAGNOSTAKIS, S. L. (1982). Biological control of chestnut blight. Science 215, 466-471.

BARroso, G. \& LABARÈre, J. (1990). Evidence for viral and naked double-stranded RNAs in the basidiomycete Agrocybe aegerita. Current Genetics 18, 231-237.

Ben-Tzvi, B. S., Koltin, Y., Mevarech, M. \& Tamarkin, A. (1984). RNA polymerase activity in virions from Ustilago maydis. Molecular and Cellular Biology 4, 188-194.

BuCK, K. W. (1975). Replication of double-stranded RNA in particles of Penicillium stoloniferum virus S. Nucleic Acids Research 2, 1889-1902.

Buck, K. W. (1986). Fungal virology-an overview. In Fungal Virology, pp. 1-84. Edited by K. W. Buck. Boca Raton: CRC Press.

FINNEGAN, P. M. \& BRown, G. G. (1986). Autonomously replicating RNA in mitochondria of maize plants with S-type cytoplasm. Proceedings of the National Academy of Sciences of the United States of America 83, 5175-5179.

Francki, R. I. B., Fauquet, C. M., Knudson, D. L. \& Brown, F. (1991). Classification and Nomenclature of Viruses. Fifth Report of the International Committee on Taxonomy of Viruses. Archives of Virology supplementum 2, 450. 
Hansen, D. R., Van Alfen, N. K., Gillies, K. \& Powell, W. A. (1985). Naked dsRNA associated with hypovirulence of Endothia parasitica is packaged in fungal vesicles. Journal of General Virology 66, 2605-2614.

LU, B. C. \& SaKaguchi, K. (1984). A unique eukaryotic DNA polymerase that transcribes single- and double-stranded RNA. Genetics 107, s65.

Maniatis, T., Fritsch, E. F. \& SAmbrooK, J. (1982). In Molecular Cloning: A Laboratory Manual. New York: Cold Spring Harbor Laboratory.

Moulinier, T., Barroso, G. \& Labarère, J. (1992). The mitochondrial genome of the basidiomycete Agrocybe aegerita: molecular cloning, physical mapping and gene location. Current Genetics 21, 499-505.

NoËL, T., Ho HUYNH, T. D. \& LABARÈRE, J. (1991). Genetic variability of the wild incompatibility alleles of the tetrapolar basidiomycete Agrocybe aegerita. Theoretical and Applied Genetics 81, 745-751.

Patrerson, J. L. (1990). Viruses of protozoan parasites. Experimental Parasitology 70, 111-113.

RAPER, C. A., RAPER, J. R. \& MILLER, R. E. (1972). Genetic analysis of the life cycle of Agaricus bisporus. Mycologia 64, 108-117.

Rogers, H. J., BuCK, K. W. \& Brasier, C. M. (1987). A mitochondrial target for double-stranded RNA in diseased isolates of the fungus that causes Dutch elm disease. Nature, London 329, 558-560.

Seroussi, E., Peery, T., Ginzberg, I. \& Koltin, Y. (1989). Detection of killer-independent dsRNA plasmids in Ustilago maydis by a simple and rapid method of extraction of dsRNA. Plasmid 21, 216-225.

Shapira, R., Chol, G. H. \& Nuss, D. L. (1991 a). Virus-like genetic organization and expression strategy for a double-stranded RNA genetic element associated with biological control of chestnut blight. EMBO Journal 10, 731-739.

Shapira, R., Choi, G. H., Hillman, B. I. \& Nuss, D. L. (1991 b). The contribution of defective RNAs to the complexity of viral-encoded double-stranded RNA populations present in hypovirulent strains of the chestnut blight fungus Cryphonectria parasitica. EMBO Journal $10,741-746$.

Sriskantha, A., Wach, M. P., Schlagnhaufer, B. \& Romaine, C. P. (1986). Synthesis of double-stranded RNA in a virus-enriched fraction from Agaricus bisporus. Journal of Virology 57, 1004-1009.

Welsh, J. D., Leibowitz, M. J. \& WickNeR, R. B. (1980). Virion DNA-independent RNA polymerase from Saccharomyces cerevisiae. Nucleic Acids Research 8, 2349-2363. 